\title{
Cystic Fibrosis-Related Diabetes Mellitus and Pregnancy: A Retrospective Study
}

\author{
Recie Davern · Gabriela Balan · Ciara Kilcoyne $\cdot$ Ciara Coveney \\ Hilary Devine · Jennifer M. Walsh · Mary Higgins · Mensud Hatunic (D)
}

Received: November 18, 2021 / Accepted: February 2, 2022 / Published online: February 21, 2022

(C) The Author(s) 2022

\begin{abstract}
Introduction: Cystic fibrosis-related diabetes mellitus (CFRDM) is becoming a more common issue in pregnancy care as the life expectancy of females living with cystic fibrosis has improved, with an increasing number of pregnancies in this population. Despite the Republic of Ireland having the highest incidence of cystic fibrosis globally, there is limited Irish data on pregnancy outcomes for those with CFRDM. This study aimed to retrospectively review maternal and foetal outcomes of pregnancies affected by maternal CFRDM.

Methods: The patient records of all women with CFRDM who attended the National Maternity Hospital Dublin for obstetric care between 2015 and 2019 were retrospectively reviewed.
\end{abstract}

R. Davern · G. Balan · C. Kilcoyne · M. Hatunic ( $₫)$ Endocrinology Department, Mater Misericordiae University Hospital, 30 Eccles Street, Dublin 7 D07XA09, Ireland

e-mail: mhatunic@mater.ie

R. Davern · G. Balan · C. Coveney · H. Devine · J. M. Walsh · M. Higgins - M. Hatunic

The National Maternity Hospital, Holles Street, Dublin, Ireland

R. Davern · G. Balan · J. M. Walsh · M. Higgins

M. Hatunic

University College Dublin, Dublin, Ireland
Results: A search of patient records identified 15 pregnancies in 12 women with CFRDM during the study period. CFRDM was diagnosed pre-conception in ten of the 15 pregnancies. Median neonatal weight at birth was lower in women with CFRDM diagnosed pre-conception compared to women diagnosed during pregnancy ( 2.8 vs. $3.02 \mathrm{~kg}$ ). The median weight gain in women with CFRDM diagnosed pre-conception was $10.9 \mathrm{~kg}$ compared to $11.9 \mathrm{~kg}$ for those diagnosed during pregnancy. The majority of women $(62.5 \%)$ with CFRDM diagnosed preconception delivered via caesarean section. Admission for $\mathrm{CF}$ exacerbations during pregnancy in women with CFRDM diagnosed pre-conception was very common (87.5\%) compared with $75 \%$ of those diagnosed during their pregnancy.

Conclusion: Women diagnosed with CFRDM were likely to require caesarean section, to be treated with insulin, and to be frequently admitted to hospital for CF exacerbations. Our review highlights the importance of good glucose control, stable cystic fibrosis before pregnancy and a multidisciplinary team approach.

Keywords: Cystic fibrosis and pregnancy; Cystic fibrosis-related diabetes; CFRDM; Diabetes in pregnancy 


\section{Key Summary Points}

Why carry out this study?

Cystic fibrosis-related diabetes mellitus (CFRDM) is becoming a more common issue in pregnancy.

There is limited data on pregnancy outcomes for those with CFRDM.

The aim of this study was to study the impact of pre-gestational diabetes on pregnancy outcomes in a large maternity hospital with a multidisciplinary team, with intention to improve diabetes in pregnancy outcomes.

\section{What was learned from the study?}

This is the first dataset on women with CFRDM during pregnancy in the Republic of Ireland.

\section{Women with a CFRDM prior to} conception are likely to be treated with insulin, have high rates of caesarean section and be frequently admitted for CF exacerbations.

Our review highlights the importance of the multidisciplinary team approach in managing these pregnancies and the need for further studies in this area.

\section{INTRODUCTION}

Cystic fibrosis (CF) is an autosomal recessive disease caused by mutations of a gene on chromosome 7 which encodes for a chloride channel in the membranes of epithelial cells [1]. The reduced chloride conductance results in viscid secretions and organ damage in the respiratory and reproductive tracts and in the pancreatic and hepatobiliary ducts. It is a progressive multisystem disease caused by a reduction in or loss of the CF transmembrane conductance regulator (CFTR) protein function.
The Republic of Ireland (hereafter referred to as Ireland) has the highest incidence (per head of general population) of CF in the world at one in 1461 people, which is threefold the rate of CF in the USA and the rest of the European Union [2]. Improved treatments for $\mathrm{CF}$ have resulted in longer survival, meaning that more women with $\mathrm{CF}$ are living into adulthood, with the median age of survival in Europe now approximately 40 years [3]. As a result of improved survival, the number of pregnancies in women with CF has been increasing in recent years [4].

The first successful birth of a baby in a woman with CF was reported in 1960 [5] and a case series of 13 pregnancies in ten women was subsequently published [6]. Of these 13 pregnancies, eight resulted in healthy deliveries at term, three were pre-term deliveries and the remaining two infants were stillborn or died shortly after birth. The knowledge of pregnancy in women with CF has expanded since these early reports, and pregnancy is no longer considered to negatively impact survival in those with CF $[7,8]$.

The development of CF-related diabetes mellitus (CFRDM) is also becoming more prevalent due to the improved survival of those living with CF [1]. CFRDM occurs in up to one half of all adults with CF [9] and has been associated with worse survival, especially in females [10]. This disorder is caused by abnormal chloride channel function, resulting in thick viscous secretions that give rise to obstructive damage to the exocrine pancreas. Progressive fibrosis and fatty infiltration ensue and destroy islet architecture, leading to insulin deficiency [11]. It is well recognised in people with CF that the first stage of insulin secretion is delayed, resulting in postprandial hyperglycaemia, which leads to impaired glucose tolerance and eventual CFRD $[12,13]$. In addition to the traditional view that CFRD is a consequence of fibrotic destruction of the pancreas as a whole, emerging evidence may implicate a role for the CFTR in the regulation of insulin secretion from the pancreatic islets. Impaired firstphase insulin responses and glucose homeostasis have also been reported in CF patients. CFTR expression in both human and mouse beta cells has been confirmed, and recent studies have 
shown differences in endocrine pancreatic morphology from birth in CF. Recent experimental evidence suggests that functional CFTR channels are required for insulin exocytosis and the regulation of membrane potential in the pancreatic beta cell, which may account for the impairments in insulin secretion observed in many CF patients [14].

A particular challenge in those with CFRDM in pregnancy is maintaining nutritional requirements of the mother and foetus while also at the same time maintaining good glycaemic control. Previously reported data have shown that aggressive treatment of hyperglycaemia during pregnancy improves maternal and foetal outcomes [15], and a similar approach has been recommended in those with CFRDM. Patelet et al. and Girault et al. both found that pregnancies occurred at younger ages in the CF population compared with the general population in France $[16,17]$.

While there are international data on pregnancy outcomes in CFRDM, despite the high incidence of CF in Ireland, only limited data are available. Therefore the aim of this study was to review maternal and foetal outcomes in our centre.

\section{METHODS}

A retrospective review of patient records for all women with CFRDM who attended the National Maternity Hospital (NMH) in Dublin for their obstetric care between 2015 and 2019 was performed. The NMH is a large tertiary level unit in the city of Dublin with nearly 7000-9000 births per year. Over 800 women attend the Diabetes and Pregnancy service, which is staffed by the full multidisciplinary team (MDT).

Women with CFRDM are cared for by an expanded MDT that includes respiratory physicians, clinical nurse specialists, specialist physiotherapists and dietitians within St Vincent's University Hospital, situated $4 \mathrm{~km}$ from the $\mathrm{NMH}$. The women included in the study attended the CF respiratory team in St. Vincent's University Hospital, Dublin pre-conception and continued follow up with this team during the pregnancy. Many women with CF attend the Obstetric unit for pre-pregnancy advice.

Routine antenatal care involved combined diabetic/obstetric clinic/CFRD clinic visits every 3-4 weeks in the first trimester, every 2-3 weeks in the second trimester and every 1-2 weeks in the third trimester. The women also submitted their glucose readings electronically on a weekly basis for review. In general, nutritional care includes monitoring maternal weight at each visit and also individual consultations with advice on enzymes, supplements, vitamins and increased nutrition from the diabetes dietician. Women usually attend both units for same day appointments, and there are clear and wellestablished lines of communication between the two halves of the whole MDT, with the woman remaining at the centre of care at all times.

Vaginal delivery was recommended in all cases where there was no obstetric contraindication. Women usually deliver in the standalone obstetric unit with support from the general medical hospital. The option of birth within the general medical hospital is reserved for those with more severe disease. Women with CF were categorised according to their diabetes status pre-conception, that is CF with diabetes diagnosed pre-pregnancy or pre-pregnancy CF with diabetes in pregnancy.

In this study, diagnosis of CFRDM was done in accordance with the American Diabetes Association standard of medical care in diabetes recommendation [18]. Women with CFRDM prior to conception were compared to those who are diagnosed during pregnancy. The outcome measures obtained from the patient record were: maternal age, nationality, baseline forced expiratory volume in one second (FEV1), mode of conception, booking weight, height, body mass index (BMI), weight in each of the trimesters, gestational weight gain, booking HBA1C and second and third trimester, treatment of diabetes, mode of delivery, gestational age at delivery, baby's birth weight and gender and rate of neonatal hypoglycaemia. Outcome measures included rate of miscarriage, mode of delivery, neonatal weight and neonatal APGAR scores at delivery. 
The data collection for this study was approved by the Research Ethics Committee National Maternity Hospital, Holles Street, Dublin, Ireland (Ref EC24.2020). Statistics analysis was performed using the Statistical Package for the Social Sciences, version 26.0 for Windows (IBM SPSS, Armonk, NY, USA). Nonparametric data are presented as medians and interquartile ranges (IQR).

\section{RESULTS}

During the study period from January 2015 to January 2019 there were 15 pregnancies identified in 12 women with CFRDM. Among these 12 women, one had three pregnancies during the study period and one had two. The median age of the women was 32 years, median duration of CF was 24 years and median was BMI $22.5 \mathrm{~kg} /$ $\mathrm{m}^{2}$; the median FEV1 was high, at $80 \%$, indicating good CF control (Table 1).

The majority of women had CFRDM prior to conception (10/15 pregnancies, 67\%), and median glycated haemoglobin (HbA1c) at the booking visit was $32 \mathrm{mmol} / \mathrm{mol}$ (IQR 32-39.5). The median HbA1c in this group by the third trimester of pregnancy was 33 (IQR 30-36) $\mathrm{mmol} / \mathrm{mol}$.

Of the 12 women included in the study, four required medically assisted conception, of which three were diagnosed with CFRDM preconception. Three of the 15 pregnancies ended

Table 1 Patient baseline characteristics at booking visit

\begin{tabular}{ll}
\hline Patient characteristics & Values $(\boldsymbol{N}=\mathbf{1 5} \text { pregnancies })^{\mathbf{a}}$ \\
\hline Age $($ years $)$ & $32(28-36)$ \\
FEV1 $(\%)$ & $80(50-97)$ \\
Weight $(\mathrm{kg})$ & $56(51.05-65.75)$ \\
BMI $\left(\mathrm{kg} / \mathrm{m}^{2}\right)$ & $22.5(21.6-25.4)$ \\
Duration of CF (years) & $24(21-30)$ \\
\hline
\end{tabular}

CR Cystic fibrosis, BMI body mass index, FEVI forced expiratory volume in the first second

${ }^{a}$ Values are presented as the median with the interquartile range (IQR) in parentheses in miscarriage (20\%) during the first trimester, of which two were in women from the CFRDM pre-conception group and one in a woman diagnosed with CFRDM during pregnancy. All remaining patients in the CFRDM pre-conception group $(n=8)$ were treated with multiple dose injection (MDI) insulin therapy during their pregnancy. In the remaining four women who were diagnosed during pregnancy, two were treated with diet and two were treated with insulin MDI. Median gestational age at delivery was 37 (29-39) weeks and only two patients delivered before 37 weeks (at 35 and 29 weeks). Five of the 12 women (42\%) were delivered via caesarean section, of whom all were diagnosed with CFRDM pre-conception with indications for caesarean section as follows: failure to progress, maternal interest, pyrexia during labour, breech presentation and previous third-degree tear. The median neonatal birth weight was $2.8 \mathrm{~kg}$ in the pre-gestational CFRD group and $3.02 \mathrm{~kg}$ in the group diagnosed with CFRDM during pregnancy ( $p$ value 0.8 ) (Table 2).

Two of 12 neonates (17\%) required admission to the neonatal intensive care unit, both were born to mothers in the CFRDM pre-conception group, and the reason for admission in both cases was premature birth. Half of the babies born to women with CFRDM pre-conception experienced neonatal hypoglycaemia compared with $25 \%$ of babies born to women diagnosed during pregnancy (Table 2). All of the neonates had Apgar scores of 9 at both 1 and 5 min.

The median weight differences between the two groups across the three trimesters are shown in Table 3 . The differences in median weight in the third trimester were not statistically significant $(p=0.4)$.

\section{DISCUSSION}

This is the first study to report outcomes for pregnant patients with CFRDM living in Ireland. Women with CFRDM diagnosed prior to conception had good glycaemic control on their first visit for antenatal care and this control was stable during pregnancy with 
Table 2 Pregnancy characteristics of the two groups of women with cystic fibrosis-related diabetes mellitus

\begin{tabular}{|c|c|c|}
\hline $\begin{array}{l}\text { Patient } \\
\text { characteristics }\end{array}$ & $\begin{array}{l}\text { Diabetes pre- } \\
\text { pregnancy }^{a}\end{array}$ & $\begin{array}{l}\text { No diabetes pre- } \\
\text { pregnancy }^{\text {a }}\end{array}$ \\
\hline & $\begin{array}{l}N=10 \\
\text { pregnancies }\end{array}$ & $\begin{array}{l}N=5 \\
\text { pregnancies }\end{array}$ \\
\hline $\begin{array}{l}\text { Medically assisted } \\
\text { conception }\end{array}$ & $3(30 \%)$ & $1(20 \%)$ \\
\hline \multirow[t]{2}{*}{ Miscarriage } & $2(20 \%)$ & $1(20 \%)$ \\
\hline & $\begin{array}{l}N=8 \\
\text { pregnancies }\end{array}$ & $\begin{array}{l}N=4 \\
\text { pregnancies }\end{array}$ \\
\hline \multicolumn{3}{|l|}{$\begin{array}{l}\text { Maternal } \\
\text { characteristics }\end{array}$} \\
\hline Insulin therapy & $8(100 \%)$ & $2(50 \%)$ \\
\hline Diet therapy & 0 & $2(50 \%)$ \\
\hline Induction of labour & $2(25 \%)$ & $2(50 \%)$ \\
\hline $\begin{array}{l}\text { Admission for CF } \\
\text { exacerbation }\end{array}$ & $7(87.5 \%)$ & $3(75 \%)$ \\
\hline $\begin{array}{l}\text { Cesarean section } \\
\text { delivery }\end{array}$ & $5(62.5 \%)$ & 0 \\
\hline \multicolumn{3}{|l|}{ Neonatal characteristics } \\
\hline $\begin{array}{l}\text { Premature birth } \\
\text { (before } 37 \text { weeks) }\end{array}$ & $2(25 \%)$ & 0 \\
\hline $\begin{array}{l}\text { Median neonatal } \\
\text { weight }(\mathrm{kg})\end{array}$ & $2.8(2.7-2.9)$ & $3.0(2.7-3.3)$ \\
\hline NICU admission & $2(25 \%)$ & 0 \\
\hline $\begin{array}{l}\text { Neonatal } \\
\text { hypoglycemia }\end{array}$ & $4(50 \%)$ & $1(25 \%)$ \\
\hline
\end{tabular}

NICU Neonatal intensive care unit

${ }^{a}$ Values are presented as the number of pregnancies $(n)$ in each group with the percentage in parentheses or as the median with the IQR

multidisciplinary team management. All our patients with CFRD had excellent diabetes control going into pregnancy and had a planned pregnancy. Diabetes control in our cohort was very good during pregnancy with insulin treatment due to good pre-pregancy care. Our
Table 3 Weight differences in women between the two groups in each trimester

\begin{tabular}{|c|c|c|}
\hline $\begin{array}{l}\text { Pregnancy } \\
\text { trimester }\end{array}$ & $\begin{array}{l}\text { Diabetes pre- } \\
\text { pregnancy } \\
(N=8)^{\mathrm{a}}\end{array}$ & $\begin{array}{l}\text { No diabetes pre- } \\
\text { pregnancy } \\
(N=4)^{\mathrm{a}}\end{array}$ \\
\hline First trimester & $52.3(50.5-63.25)$ & $58.8(57.1-65.7)$ \\
\hline Second trimester & $53.1(51.09-55.8)$ & $59.4(58.4-65.4)$ \\
\hline $\begin{array}{l}\text { Last weight } \\
\text { recorded in } \\
\text { third trimester }\end{array}$ & $63.3(58.7-78.6)$ & $70.7(66.0-76.7)$ \\
\hline
\end{tabular}

patients did not experience preeclampsia or eclampsia. There were low levels of miscarriage in our cohort, but these are consistent with data in our institution for the general population. Half of the women who had CFRDM prior to pregnancy had a caesarean section. The weight gain of both groups during pregnancy was in line with weight gain reported previously [19]. Half of all women with CFRDM diagnosed preconception had babies who experienced neonatal hypoglycaemia. High numbers of participants in our cohort required admission for CF exacerbations, and this highlights the need for a multidisciplinary approach to CFRDM pregnancies to ensure any exacerbations or complications are diagnosed and treated early to prevent adverse outcomes.

Many pregnancies in women with CFRDM have been reported in the literature, and it is clear that while the outcome for the baby is generally good and some mothers do very well, others find that either their CF complicates the pregnancy or it is adversely affected by the pregnancy [20]. In the UK, available evidence on pre-pregnancy in wwCF from the Obstetric Surveillance System data did not capture all wwCF and their pre-pregnancy clinical characteristics, such as BMI, lung function or genotype [21]. Recently published pregnancy rates and outcomes in women with CF in the UK showed that compared with the general population, women with CF had pregnancy rates that were 
about one-third of those in the general population, with favourable outcomes, and have increased for eligible women post-ivacaftor [22].

Our study is limited by its small numbers, making it hard to generalise the data to the wider CFRDM population. The statistical analysis was also limited by the small study size. However, despite this limitation, we found that our data are consistent with previously published results.

\section{CONCLUSIONS}

This is the first Irish dataset on women with CFRDM during pregnancy. It shows that those with a CFRDM prior to conception are likely to be treated with insulin, have high rates of caesarean section and are frequently admitted for CF exacerbations. Our review highlights the importance of good pre-pregnancy CF control, good glucose control and a multidisciplinary team approach, as well as the need for further studies in this area.

\section{ACKNOWLEDGEMENTS}

Funding. No funding or sponsorship was received for this study or publication of this article.

Authorship. All named authors meet the International Committee of Medical Journal Editors (ICMJE) criteria for authorship for this article, take responsibility for the integrity of the work as a whole, and have given their approval for this version to be published.

Author Contributions. RD, GB and CK performed the analysis and interpretation of the data, and drafted the manuscript. CC and HD collected the data and participated in patients' care. JMW, $\mathrm{MH}$ and $\mathrm{MH}$ were responsible for patients' care and the design of this study. $\mathrm{MH}$ is the guarantor of this work and, as such, had full access to all the data in the study and takes responsibility for the integrity of the data and the accuracy of the data analysis.
Prior Presentation. This submission was previously presented as a poster at the Irish Endocrine Society 43rd Annual Meeting 11-12 October 2019 (Irish J Med Sci Suppl P-15).

Disclosures. Recie Davern, Gabriela Balan, Ciara Kilcoyne, Ciara Coveney, Hilary Devine, Jennifer M Walsh, Mary Higgins and Mensud Hatunic have no conflict of interests to declare.

Compliance with Ethics Guidelines. The data collection for this study was approved by the Research Ethics Committee National Maternity Hospital, Holles Street, Dublin, Ireland (Ref EC24.2020).

Data Availability. The datasets generated and analysed during the study are not publicly available due European GDPR law.

Open Access. This article is licensed under a Creative Commons Attribution-NonCommercial 4.0 International License, which permits any non-commercial use, sharing, adaptation, distribution and reproduction in any medium or format, as long as you give appropriate credit to the original author(s) and the source, provide a link to the Creative Commons licence, and indicate if changes were made. The images or other third party material in this article are included in the article's Creative Commons licence, unless indicated otherwise in a credit line to the material. If material is not included in the article's Creative Commons licence and your intended use is not permitted by statutory regulation or exceeds the permitted use, you will need to obtain permission directly from the copyright holder. To view a copy of this licence, visit http://creativecommons.org/licenses/by$\mathrm{nc} / 4.0 /$.

\section{REFERENCES}

1. Goddard J, Bourke SJ. Cystic fibrosis and pregnancy. Obstet Gynaecol. 2009;11:19-24.

2. Devaney J, Glennon M, Farrell G, et al. Cystic fibrosis mutation frequencies in an Irish population. Clin Genet. 2003;63(2):121-5. 
3. Elborn JS. Cystic fibrosis. Lancet. 2016;388: 2519-31.

4. Goss CH, Van Devanter DR. CFTR modulators and pregnancy: our work has only just begun. J Cyst Fibros. 2016;15:6-7.

5. Siegel B, Siegel S. Pregnancy and delivery in a patient with cystic fibrosis of the pancreas. Obstet Gynecol. 1960;16:439-40.

6. Grand RJ, Talamo RC, Di SantAgnese PA, et al. Pregnancy in cystic fibrosis of the pancreas. JAMA. 1966;195:117-24.

7. Gilljam M, Antoniou M, Shin J, Dupuis A, Corey M, Tullis DE. Pregnancy in cystic fibrosis. Fetal and maternal outcome. Chest. 2000;118:85-91.

8. Goss $\mathrm{CH}$, Rubenfeld GD, Otto K, Aitken ML. The effect of pregnancy on survival in women with cystic fibrosis. Chest. 2003;124:1460-8.

9. Moran A, Dunitz J, Nathan B, Saeed A, Holme B, Thomas W. Cystic fibrosis-related diabetes: current trends in prevalence, incidence, and mortality. Diabetes Care. 2009;32:1626-31.

10. Plant BJ, Goss CH, Plant WD, Bell SC. Management of comorbidities in older patients with cystic fibrosis. Lancet Respir Med. 2013;1:164-74.

11. Kelly A, Moran A. Update on cystic fibrosis-related diabetes. J Cyst Fibros. 2013;12:318-31.

12. Boudreau V, Reynaud Q, Dubois CL, et al. Screening for cystic fibrosis-related diabetes: matching pathophysiology and addressing current challenges. Can J Diabetes. 2016;40:466-70.

13. Grulich-Henn J, Klose D. Understanding childhood diabetes mellitus: new pathophysiological aspects. J Inherit Metab Dis. 2018;41:19-27.
14. Koivula FNM, McClenaghan NH, Harper AGS, Kelly C. Islet-intrinsic effects of CFTR mutation. Diabetologia. 2016;59(7):1350-5.

15. Crowther CA, Hiller JE, Moss JR, et al. Effect of treatment of gestational diabetes mellitus on pregnancy outcomes. N Engl J Med. 2005;352:2477-86.

16. Girault A, Blanc J, Gayet V, Goffinet F, Hubert D. Maternal and perinatal outcomes of pregnancies in women with cystic fibrosis-a single centre casecontrol study. Respir Med. 2016;113:22-7.

17. Patel EM, Swamy GK, Heine RP, Kuller JA, James AH, Grotegut CA. Medical and obstetric complications among pregnant women with cystic fibrosis. Am J Obstet Gynecol. 2015;212(98):e1-9.

18. American Diabetes Association. Standards of medical care in diabetes-2015 Diabetes Care. 2015;38(Suppl_1):S4

19. Gillet D, de Braekeleer M, Bellis G, Durieu I. Cystic fibrosis and pregnancy. Report from French data (1980-1999). BJOG. 2002;109:912-8.

20. Edenborough FP, Borgo G, Knoop C, et al. Guidelines for the management of pregnancy in women with cystic fibrosis. J Cyst Fibros. 2008;7(Suppl 1): S2-32.

21. Ashcroft A, Chapman S, Mackillop L. The outcome of pregnancy in women with cystic fibrosis: a UK population-based descriptive study. BJOG Int J Obstet Gynaecol. 2020;127:1696-703.

22. Esan OB, Schlüter DK, Phillips R, et al. Pregnancy rates and outcomes in women with cystic fibrosis in the UK: comparisons with the general population before and after the introduction of disease-modifying treatment, 2003-17. BJOG. 2021. https://doi. org/10.1111/1471-0528.16957. 